\title{
Cross-Sectional Associations Between Dietary Antioxidant Vitamins C, E and Carotenoid Intakes and Sarcopenic Indices in Women Aged 18-79 Years
}

\author{
A. A. Welch ${ }^{1}$ (1) $\cdot$ A. Jennings ${ }^{1} \cdot$ E. Kelaiditi ${ }^{1,2} \cdot$ J. Skinner $^{1} \cdot$ C. J. Steves ${ }^{3}$
}

Received: 1 August 2019 / Accepted: 22 November 2019 / Published online: 7 December 2019

(c) The Author(s) 2019

\begin{abstract}
The prevalence of sarcopenia is increasing in aging populations, so prevention is critical. Vitamins (A, C, E and carotenoids) modify skeletal muscle via protein and collagen synthesis and anti-inflammatory activities. Previous studies have not investigated intake of these vitamins in relation to sarcopenic indices in both younger and older-aged women. Indices of skeletal muscle mass (as fat-free mass (FFM) relative to body size) were measured using DXA and leg explosive power (LEP) using the Nottingham Power Rig in 2570 women aged 18-79 years. Adjusted measures of skeletal muscle were calculated according to quintiles of vitamin C, E, retinol and carotenoid intake, derived from Food Frequency Questionnaires, after stratification by age. Higher vitamin $\mathrm{C}$ intake was associated with significantly higher indices of FFM and LEP, (Q5-Q1 =2.0-12.8\%, $P<0.01-0.02)$. Intakes of total and individual carotenoids were significantly associated with indices of FFM and LEP

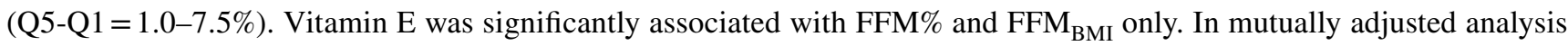
with vitamin $\mathrm{C}$, total carotene, vitamin $\mathrm{E}$ and protein in the model, the strongest associations were with vitamin $\mathrm{C}$. These associations were stronger in younger women ( $<65$ years). For the first time, our research shows higher dietary intakes of antioxidant vitamins, particularly vitamin $\mathrm{C}$, is associated with higher skeletal muscle mass and power in free-living women. These findings have relevance for the treatment and prevention of frailty and sarcopenia throughout adulthood.
\end{abstract}

Keywords Sarcopenia · Diet · Vitamin C · Vitamin E · Carotenes · Vitamin A · Skeletal muscle $\cdot$ Grip strength

\section{Background and Aims}

Across the world, populations are aging rapidly leading to increased prevalence of sarcopenia and frailty, conditions that also increase the risk of osteoporosis, falls, fractures

Electronic supplementary material The online version of this article (https://doi.org/10.1007/s00223-019-00641-x) contains supplementary material, which is available to authorized users.

A. A. Welch

a.welch@uea.ac.uk

1 Department of Epidemiology \& Public Health, Norwich Medical School, University of East Anglia, Norwich Research Park, Norwich, Norfolk NR4 7TJ, UK

2 Faculty of Sport, Health and Applied Science, St Mary's University, Waldegrave Road, Twickenham, London TW1 4SX, UK

3 Department of Twin Research and Genetic Epidemiology, King's College, London, UK and mortality, leading to longer and more expensive hospital stays. These conditions also impact adversely on quality of life for individuals [1]. The estimated prevalence of sarcopenia in the community is $1-29 \%$ in people over the age of 60 years, which rises to $17.7-87 \%$ in those living in assisted or residential or care facilities [1-3]. Frailty is estimated to affect $25 \%$ of people over the age of 80 years. We need, therefore, strategies to prevent the gradual age-related decline in skeletal muscle mass and function, or sarcopenic indices, that start in middle age to maintain intrinsic capacity in older adults [4].

The established mechanisms of aging of skeletal muscle include increases in circulating cytokines and production of reactive oxygen species (ROS), with age which have detrimental effects on synthesis of protein as well as direct cellular damage of skeletal muscle fibres and DNA [5]. Additionally, there are changes to the proportion, quality and viscoelastic properties of the different types of collagen that form the important structural component of skeletal muscle cells, connective tissues and tendons during aging [6]. As endogenous 
antioxidant efficiency is reduced with aging, and skeletal muscle generates the greatest quantities of ROS in the body, exogenous antioxidant vitamins have potential importance for skeletal muscle health.

Dietary antioxidant vitamins (A, C, E and carotenoids) are, therefore, promising candidates for the prevention and treatment of age-related loss of mass and function. These vitamins influence skeletal muscle and function through their roles as exogenous antioxidant and anti-inflammatory agents. In addition, vitamin $\mathrm{C}$ is involved in collagen and carnitine synthesis and retinol in protein metabolism, collagen formation, and lipid oxidation $[7,8]$.

To date, dietary treatments for sarcopenia and frailty have focused largely on interventions with protein intake, with or without resistance exercise, which is important for skeletal muscle but the effectiveness of intervention studies in individuals with sarcopenia and frailty have been mixed $[9,10]$. As there are no effective pharmacological treatments for sarcopenia, frailty and the loss of skeletal muscle mass and function with age, identifying other dietary factors to prevent or attenuate losses of muscle mass and function in middle and early old age is important.

Whilst limited previous research has studied nutritional intake or blood concentrations of vitamin A, C, E or carotenoids and measures of skeletal muscle mass or function in older-aged populations, none has measured their relative effectiveness in relation to a range of indices of both skeletal mass and function in young as well as in older-aged women [11-19]. Therefore, the purpose of this study was to first, understand the associations between: (i) dietary vitamins $\mathrm{C}, \mathrm{E}$ and $\mathrm{A}$ and (ii) the full range of dietary carotenoids; $\alpha$-carotene, $\beta$-carotene, $\beta$-cryptoxanthin, lycopene, lutein and zeaxanthin and indices of skeletal muscle mass [i.e. Fat Free Mass Index (FFMI), percentage fat-free mass (FFM\%) and fat-free mass adjusted for body mass index $\left(\mathrm{FFM}_{\mathrm{BMI}}\right)$ ], and function [i.e. hand grip strength, arm muscle quality and leg explosive power (LEP)] in a population of women with a wide age range. Second, to understand whether these associations differed in young women compared with those over the age of 65 years, third to estimate the relationship between the inflammatory cytokine C-reactive protein (CRP) and indices of skeletal muscle health and fourthly, to determine the relative associations of vitamins A, C, E, total carotene and protein by including all the nutrients in the same statistical models to determine which of the vitamins was the most strongly associated with the indices of skeletal muscle health.

\section{Methods}

The TwinsUK registry is an ongoing population study of approximately 12,000 male and female (83\%) twins, aged 18-103 years who are representative of singleton populations in the United Kingdom [20]. Data were used from 2570 women who had completed a food frequency questionnaire (FFQ) and attended for dual-energy X-ray absorptiometry (DXA) measurements between 1996 and 2000. Within this group, there were 1914 individuals with measures of leg explosive power and 1658 individuals with measures of high sensitivity C-reactive protein (hs-CRP). Between 2005 and 2008, 949 women completed an FFQ and had grip strength measured (including 512 individuals from the first cohort) (Supplementary Fig. 1). Ethical approval was obtained from St. Thomas's Hospital Research Ethics Committee and informed consent was acquired from all participants.

\section{Dietary Intake}

Participants completed a 131 item-validated FFQ with nutrient values calculated using the UK national nutrient database and a database of the carotenoid composition of foods [21, 22]. Individuals were excluded from the dietary analyses if answers to $>10$ food items were left blank or the ratio of estimated total energy intake to the estimated basal metabolic rate fell 2 SDs outside the mean ratio. Energyreporting quality was estimated using the ratio of reported energy intake (EI) to estimated energy expenditure (EER), the EI:EER ratio expressed as the percentage of EI to EER, was calculated and was included as a covariate for adjustment in the statistical analyses [23].

\section{Muscle Mass, Strength and Power}

Fat-free mass (FFM) was measured by DXA scans (Hologic QDR-2000 DXA scanner, Hologic Inc., Waltham, MA, USA) and adjusted to body size using the following calculations: FFMI: FFM (kg)/ height $\left(\mathrm{m}^{2}\right)$ [1], FFM\%: FFM $(\mathrm{kg}) /$ weight $(\mathrm{kg}) * 100$ and $\mathrm{FFM}_{\mathrm{BMI}}:$ FFM $(\mathrm{kg}) / \mathrm{BMI}(\mathrm{kg} /$ $\left.\mathrm{m}^{2}\right)$. FFM $(\mathrm{kg})$ divided by BMI $\left(\mathrm{kg} / \mathrm{m}^{2}\right)\left(\mathrm{FFM}_{\mathrm{BMI}}\right)$ takes into account the increase in body size, scaled for height and adjusting FFM for BMI is likely to set meaningful cutoff points for clinical use [1]. Isometric grip strength was assessed using a Jamar hand grip dynamometer (Sammons, Preston, UK) on the dominant arm with reproducibility assessed by repeated measurement on 24 individuals (CV of 11.4\%) [24] and adjusted for mean arm lean mass as arm muscle quality (grip strength $(\mathrm{kg}) /$ mean arm lean mass $(\mathrm{kg})$. LEP was measured using the Nottingham Power Rig which assesses the force and velocity of muscle contraction from the quadriceps, normalised for body weight (LEP (watts)/ weight $(\mathrm{kg})$ ) [25]. LEP is validated with high reliability (reliability coefficient 0.97 , coefficient of variation $9.4 \%$, over one week period in adults) [25]. 


\section{C-reactive Protein}

Circulating hs-CRP was measured by a highly sensitive automated microparticle capture enzyme immunoassay, standardised on the World Health Organisation International Reference Standard for CRP immunoassay as previously described [26].

\section{Covariates}

Information on lifestyle, medication use, menopausal status, and demographic variables were obtained using standardised nurse-administered questionnaires. Weight and height were measured to the nearest $0.1 \mathrm{~kg}$ and to the nearest $0.5 \mathrm{~cm}$, respectively. BMI was calculated as weight in kilograms $(\mathrm{kg})$ divided by height in meters squared $\left(\mathrm{m}^{2}\right)$. Leisure- and work-time physical activity was self-reported using a questionnaire significantly correlated with in depth assessments of physical activity in a subset of this cohort [27]. For participants in the grip strength group ( $n=949$ women) who had missing data on physical activity $(N=10)$, the General Practice Physical Activity Questionnaire (GPPAQ) was used. This was based on the original physical activity index developed by the European Prospective Investigation into Cancer and Nutrition (EPIC) cohort. The EPIC physical activity index was previously validated against heart rate monitoring in two independent studies [28].

\section{Statistical Analyses}

Descriptive statistics (means \pm SDs or $\%$ (n)) were analysed for all participants and for those under 65 years $(n=2346)$ and $\geq 65$ years $(n=224)$. Multivariate regression analysis was used to calculate statistical trends and adjusted values (least square means) for FFM\%, FFMI, FFM BMI $_{\text {, LEP, }}$ arm muscle quality and hs-CRP (outcomes) classified by quintile of dietary vitamins $\mathrm{C}, \mathrm{E}$ and $\mathrm{A}$ and dietary carotenoids; $\alpha$-carotene, $\beta$-carotene, $\beta$-cryptoxanthin, lycopene, lutein and zeaxanthin (exposures). The percentage difference between quintiles 1 and 5 was calculated as a percentage of the value in quintile 1 . As physical activity and smoking habit were related to indices of skeletal muscle the analyses were adjusted for physical activity and smoking habit. All models were adjusted for age (years), physical activity (active, moderately active, inactive), smoking status (never, former, current), energy intake ( $\mathrm{kcal} / \mathrm{d}$ ) and potential misreporting of energy intake (EI:EER). FFMI was adjusted for age (years), physical activity (active, moderately active, inactive), smoking status (never, former, current), energy intake $(\mathrm{kcal} / \mathrm{d})$, potential mis-reporting of energy intake (EI:EER) and fat mass (kg). LEP and arm muscle quality were adjusted for age (years), physical activity (active, moderately active, inactive), smoking status (never, former, current), energy intake ( $\mathrm{kcal} / \mathrm{d})$, potential mis-reporting of energy intake (EI:EER) and menopausal status (pre-menopausal/ post-menopausal), use of HRT (yes/no) and height (m). High sensitivity (hs) CRP was adjusted for age (years), physical activity (active, moderately active, inactive), smoking status (never, former, current), energy intake ( $\mathrm{kcal} / \mathrm{d}$ ), potential mis-reporting of energy intake (EI:EER), and BMI, use of anti-inflammatory medications (yes/no) and HRT (yes/no). Values for hs-CRP were skewed and therefore, natural log-transformed values were used for the analyses.

In analysis stratified by age, we also assessed the associations of FFM\%, FFMI, FFM ${ }_{\mathrm{BMI}}$ and LEP with quintiles of intake for those under 65 years $(n=2346)$ and tertiles for those $\geq 65$ years $(n=224)$. The data for those $\geq 65$ years was analysed for tertiles due to the smaller number of women in this group. For these and the comparative analyses we only considered vitamins A, C, E, total carotene and protein intakes as these demonstrated the greatest associations, as shown in Table 2. In additional analyses, to compare the relative associations of vitamins $\mathrm{A}, \mathrm{C}, \mathrm{E}$, total carotene and protein we included all these nutrients in the same statistical models and standardised the values for FFM\%, FFMI, $\mathrm{FFM}_{\mathrm{BMI}}$ and LEP using Z-scores. Values for the FFM indices and LEP were also adjusted for covariates as described previously, and as in the models shown in Table 3.

Values in the text are means \pm SE. A $P$ value $<0.05$ was considered statistically significant. $P$ trend was calculated from the multivariable regression across quintiles of intake of the nutrients. All analyses were performed with Stata statistical software version 14.0 (Stata Corp, College Station, TX) and included the robust cluster regression option in STATA to account for clustering within twin pairs.

\section{Results}

The characteristics of the participants are presented in Table 1 , stratified by age ( $<65$ years and $\geq 65$ years). The mean age $( \pm \mathrm{SD})$ of participants was $48.37 \pm 12.7$ years and mean $( \pm \mathrm{SD}) \mathrm{BMI}$ was $24.9 \pm 4.14 \mathrm{~kg} / \mathrm{m}^{2}$. More than onehalf of the participants were moderately active $(53.9 \%)$, and $18.2 \%$ were current smokers. In multivariable analyses, women in the highest quintile of vitamin $\mathrm{C}$ intake had signficantly higher FFM\%, FFMI, FFM BMI $_{\text {and LEP, compared }}$ to those in the lowest quintile (Table 2). Specifically, FFM\% was $1.4 \%$ higher $( \pm 0.4 P$-trend $<0.001)$, FFMI was $0.4 \mathrm{~kg} /$ $\mathrm{m}^{2}$ higher $( \pm 0.1 P$-trend $=0.002), \mathrm{FFM}_{\mathrm{BMI}}$ was $0.03 \mathrm{~kg} / \mathrm{kg} /$ $\mathrm{m}^{2}$ higher $( \pm 0.01 P$-trend $=0.023)$ and LEP was $10.9 \mathrm{w} /$ $\mathrm{kg}$ higher $( \pm 2.6 P$-trend $<0.001)$, when comparing extreme 
intake quintiles. In terms of vitamin E, FFM\% (Q5-Q1 $1.6 \% \pm 0.5 P$-trend $=0.002)$ and $\mathrm{FFM}_{\mathrm{BMI}}(\mathrm{Q} 5-\mathrm{Q} 10.06 \pm 0.02$ $P$-trend $=0.002$ ) were positively associated with intakes. For total carotene, associations were also significant for FFM\% (Q5-Q1 0.6\% $\pm 0.4 P$-trend $=0.028)$, FFMI (Q5-Q1 $0.2 \pm 0.1$ $P$-trend $=0.012)$ and LEP $(\mathrm{Q} 5-\mathrm{Q} 16.4 \pm 2.7 P$-trend $=0.011)$. The results of the associations between the nutrients and arm muscle quality were non-significant ranging from a beta coefficient $(95 \% \mathrm{CI})$ of $-0.075(-0.199,0.048)$ per quintile for vitamin $\mathrm{C}$ intake $(P$-trend $=0.231)$ to $0.036(-0.150$, $0.222)$ per quintile for vitamin $\mathrm{E}$ intake $(P$-trend $=0.705)$. The results of the associations between the nutrients and hs-CRP were also non-significant ranging from a beta coefficient $(95 \% \mathrm{CI})$ of $-0.008(-0.046,0.029)$ per quintile for vitamin $\mathrm{C}$ intake $(P$-trend $=0.666)$ to $-0.023(-0.070$, $0.025)$ per quintile for vitamin $\mathrm{E}$ intake $(P$-trend $=0.349)$. Also no associations were observed for vitamin A (measured as retinol).

\section{Individual Carotenoids}

Intakes of all the individual carotenoids, with the exception of leutein + zeaxanthin, were significantly associated with FFMI. The strongest association was observed for $\alpha$-carotene intake (Q5-Q1 $0.24 \mathrm{~kg} / \mathrm{m}^{2} \pm 0.1 P$-trend $=0.03$, $1.6 \%)$. Significant associations were also found with FFM\% for $\beta$-cryptoxthanin and with FFM\% and $\mathrm{FFM}_{\mathrm{BMI}}$ for lutein and zeaxthanin, with interquintle differences ranging from 1.1 to $7.2 \%$. LEP was associated significantly with the carotenoids, with the exception of $\alpha$-carotene, with differences ranging from 6.3 to $7.5 \%$ when comparing extreme quintiles of intake.

\section{Age-Stratified Analyses}

In age-stratified analyses, we observed that associations between vitamin $\mathrm{C}$ and $\mathrm{E}$ with FFM\% were observed in the younger $(<65$ years) but not the older $(\geq 65$ years $)$ subset (Table 3 ). Specifically, vitamin $C$ was associated with a $0.3 \%(95 \%$ CI $0.1,0.5 P$-trend $=0.002)$ and vitamin $E$ with a $0.4 \%(95 \%$ CI $0.2,0.7 P$-trend $=0.001)$ higher FFM\% per quintile of intake. Likewise, associations between vitamin C (2.3 95\% CI 1.1, 3.6 per quintile $P$-trend $<0.001)$ and total carotene $(1.795 \%$ CI $0.4,2.9$ per quintile $P$-trend $=0.009)$ and LEP $(\mathrm{w} / \mathrm{kg})$ were only observed in participants aged $<65$ years. Similar trends were also found with FFMI and FFM/BMI, although there was no significant association between FFM/BMI and vita$\min \mathrm{C}$ in those $<65$ years.

\section{Standardised Analyses}

In standardised analyses, we compared the relative associations of vitamins $\mathrm{C}, \mathrm{E}$, retinol and total carotene with FFM\% and LEP (Figs. 1, 2). Associations between vitamin $\mathrm{C}$ and FFM\% and LEP were maintained after mutual adjustment for the other nutrients, including protein $(\mathrm{FFM} \% 0.17 \mathrm{SD} \pm 0.07 P$-trend $=0.013$ and LEP 0.27 $\mathrm{SD} \pm 0.08 P$-trend $=0.004)$. A significant negative association with protein was observed for FFM\% $(-0.18 \mathrm{SD} \pm 0.06 P$-trend $<0.001), \mathrm{FFM}_{\mathrm{BMI}}$ $-0.27 \pm 0.06 P$-trend $<0.001$ and LEP $(-0.14 \mathrm{SD} \pm 0.07$ $P$-trend $=0.007)$ but the association with FFMI was not
Fig. 1 The relative associations of vitamin $\mathrm{C}$, vitamin $\mathrm{E}$, retinol, carotene and protein with percentage fat-free mass in 2570 females aged $18-79$ years, stratified by age ${ }^{1}$. Values represent the difference in standardised values of percentage fat-free mass between participants in Q5 vs Q1 of intake (T3$\mathrm{T} 1$ for $>65$ years sub-group) with all nutrients included in the model. Values were also adjusted for age, physical activity, smoking status, energy intake and underreporting. * $P$-trend $<0.05$

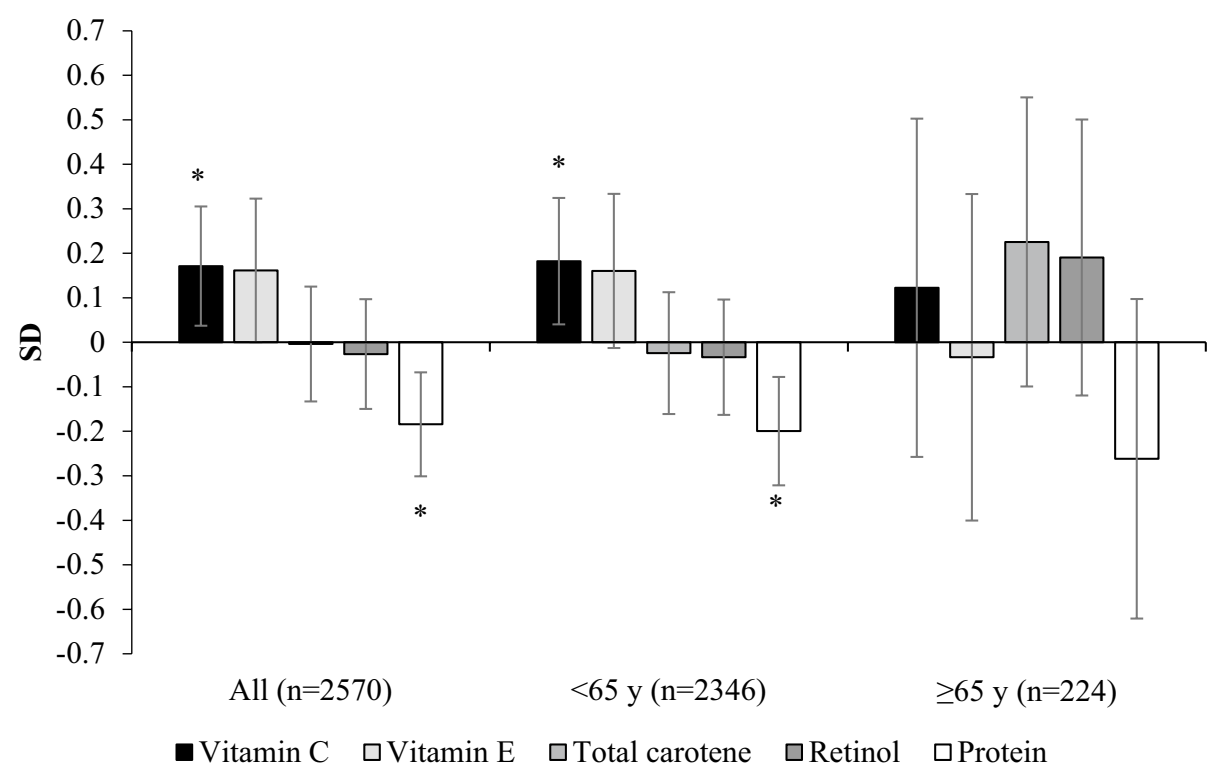


Table 1 Characteristics and dietary intakes of $n=2570$ females aged 18-79 years, stratified by age ${ }^{\mathrm{a}}$

\begin{tabular}{|c|c|c|c|}
\hline Characteristic & All & $<65$ years & $\geq 65$ years \\
\hline$n=$ & 2570 & 2346 & 224 \\
\hline Age (years) & $48.3 \pm 12.7$ & $46.5 \pm 11.6$ & $68.0 \pm 2.81$ \\
\hline BMI $\left(\mathrm{kg} / \mathrm{m}^{2}\right)$ & $24.9 \pm 4.14$ & $24.8 \pm 4.11$ & $26.1 \pm 4.23$ \\
\hline Fat mass $(\mathrm{kg})$ & $22.7 \pm 7.87$ & $22.5 \pm 7.90$ & $25.0 \pm 7.26$ \\
\hline Fat free mass $(\%)$ & $61.1 \pm 6.50$ & $61.4 \pm 6.46$ & $58.0 \pm 6.08$ \\
\hline Fat Free Mass Index $\left(\mathrm{kg} / \mathrm{m}^{2}\right)$ & $15.0 \pm 1.72$ & $15.0 \pm 1.71$ & $15.0 \pm 1.80$ \\
\hline Fat-free mass/ BMI $\left(\mathrm{kg} / \mathrm{kg} / \mathrm{m}^{2}\right)$ & $1.62 \pm 0.23$ & $1.63 \pm 0.23$ & $1.47 \pm 0.19$ \\
\hline Leg explosive power ${ }^{\mathrm{b}}$ (watts) & $89.8 \pm 36.8$ & $91.3 \pm 36.7$ & $67.5 \pm 30.8$ \\
\hline Leg explosive power ${ }^{\mathrm{b}}$ (watts $/ \mathrm{kg}$ ) & $90.9 \pm 36.5$ & $92.4 \pm 36.3$ & $68.3 \pm 31.6$ \\
\hline hs-CRP ${ }^{c}(\mathrm{mg} / \mathrm{L})$ & $2.49 \pm 2.30$ & $2.47 \pm 2.30$ & $2.72 \pm 2.26$ \\
\hline Grip strength $^{\mathrm{d}}(\mathrm{kg})$ & $28.8 \pm 5.95$ & $30.1 \pm 5.66$ & $25.3 \pm 5.20$ \\
\hline Energy intake (kcal/d) & $1979 \pm 524$ & $1978 \pm 533$ & $1989 \pm 415$ \\
\hline Protein (\% energy) & $16.6 \pm 2.62$ & $16.6 \pm 2.62$ & $16.9 \pm 2.68$ \\
\hline Vitamin $C(\mathrm{mg} / \mathrm{d})$ & $155 \pm 80.2$ & $154 \pm 80.4$ & $165 \pm 78.3$ \\
\hline Vitamin E (mg/d) & $11.4 \pm 4.57$ & $11.3 \pm 4.60$ & $11.7 \pm 4.26$ \\
\hline Total carotene $(\mu \mathrm{g} / \mathrm{d})$ & $3448 \pm 1944$ & $3416 \pm 1964$ & $3777 \pm 1688$ \\
\hline$\alpha$-Carotene $(\mu \mathrm{g} / \mathrm{d})$ & $559 \pm 416$ & $554 \pm 418$ & $621 \pm 389$ \\
\hline$\beta$-Carotene $(\mu \mathrm{g} / \mathrm{d})$ & $3091 \pm 1757$ & $3062 \pm 1775$ & $3398 \pm 1529$ \\
\hline Retinol ( $\mu \mathrm{g} / \mathrm{d})$ & $559 \pm 789$ & $545 \pm 793$ & $700 \pm 728$ \\
\hline$\beta$-Cryptoxanthin $(\mu \mathrm{g} / \mathrm{d})$ & $200 \pm 194$ & $201 \pm 197$ & $192 \pm 166$ \\
\hline Lycopene $(\mu \mathrm{g} / \mathrm{d})$ & $1347 \pm 958$ & $1364 \pm 968$ & $1165 \pm 820$ \\
\hline Lutein + zeaxanthin $(\mu \mathrm{g} / \mathrm{d})$ & $2267 \pm 1478$ & $2253 \pm 1501$ & $2413 \pm 1204$ \\
\hline Underreporting (EI:EER, \%) & $87.4 \pm 24.6$ & $86.7 \pm 24.6$ & $95.0 \pm 24.2$ \\
\hline Physical activity (active, \%) & $24.2 \%(622)$ & $23.9 \%(561)$ & $27.2 \%(61)$ \\
\hline Moderately active (\%) & $53.9 \%(1385)$ & $54.2 \%(1271)$ & $50.9 \%(114)$ \\
\hline Inactive (\%) & $21.9 \%(563)$ & $21.9 \%(514)$ & $21.9 \%(49)$ \\
\hline Smoking status (current, \%) & $18.2 \%(468)$ & $19.1 \%(449)$ & $8.48 \%(19)$ \\
\hline Menopausal status (post-menopausal, \%) & $47.4 \%(1218)$ & $42.5 \%$ (997) & $98.7 \%(221)$ \\
\hline Anti-inflammatory medication ${ }^{\mathrm{c}}(\mathrm{yes}, \%)$ & $6.15 \%(102)$ & $6.06 \%(90)$ & $6.98 \%(12)$ \\
\hline Hormone replacement therapyc (yes, \%) & $6.33 \%(105)$ & $6.33 \%(94)$ & $6.40 \%(11)$ \\
\hline
\end{tabular}

EI:EER ratio of reported energy intake to estimated energy requirements

${ }^{a}$ Values are mean \pm SD or $\%(n), n=2570$

Values for a subset of ${ }^{\mathrm{b}} 1914$

${ }^{\mathrm{c}} 1658$

${ }^{\mathrm{d}} 949$ participants significant $0.05 \mathrm{SD} \pm 0.06 P$-trend $=0.390$. The results for vitamin $\mathrm{E}$, not shown in the figures were: FFMI $-0.05 \mathrm{SD} \pm 0.08 P$-trend $=0.487$ and $\mathrm{FFM}_{\mathrm{BMI}} 0.19 \pm 0.09$ $P$-trend $=0.025$.

Total vegetable intake was a significant source of vitamins $\mathrm{C}, \mathrm{E}$ and carotene intake, however, the specific vegetables that contributed differed for each nutrient (Fig. 3). For vitamin $\mathrm{C}$ the main contributors were peppers, Brussels sprouts and broccoli, for vitamin $\mathrm{E}$ avocado, mushrooms and spinach, and for carotene, carrots and spinach. Fruit intake also contributed to vitamin $\mathrm{C}$ intake, and for vitamin $\mathrm{E}$, the food groups cakes and biscuits and whole grain cereals contributed more to intake than vegetables.

\section{Discussion}

Our findings of significant associations between higher intakes of vitamin $\mathrm{C}$, total carotene and specific carotenoids and improved sarcopenic indices of skeletal muscle; FFM and LEP were found in a cohort of women with a wide age range (18-79 years). The scale of the associations for these vitamins ranged from 1.0 to $3.2 \%$ for indices of FFM and from 6.3 to $12.8 \%$ for LEP, comparing the highest and lowest intakes and adjusting for relevant covariates including age. This highlights the potential clinical importance of the findings as the yearly losses of FFM 
Table 2 Fat free mass indices and leg explosive power by quintile of nutrient intake in 2570 females aged $18-79$ years $^{\mathrm{a}}$

\begin{tabular}{llllll}
\hline & \multicolumn{1}{c}{ Intake $^{\mathrm{b}}$} & FFM $(\%)$ & FFM/BMI & FFMI $\left(\mathrm{kg} / \mathrm{m}^{\mathrm{b}}\right)$ & LEP $^{\mathrm{c}}(\mathrm{w} / \mathrm{kg})$ \\
\hline \multicolumn{2}{l}{ Vitamin C $(\mathrm{mg} / \mathrm{d})$} & & & & \\
Q1 & $68.8 \pm 16.4$ & $60.4(59.8,60.9)$ & $1.60(1.58,1.62)$ & $14.8(14.7,15.0)$ & $85.2(81.8,88.6)$ \\
Q2 & $108 \pm 9.43$ & $60.9(60.4,61.4)$ & $1.61(1.59,1.63)$ & $15.0(14.9,15.2)$ & $90.8(87.2,94.4)$ \\
Q3 & $141 \pm 10.1$ & $61.1(60.6,61.6)$ & $1.62(1.60,1.64)$ & $15.0(14.9,15.1)$ & $90.1(86.4,93.8)$ \\
Q4 & $181 \pm 13.8$ & $61.3(60.8,61.8)$ & $1.62(1.60,1.64)$ & $15.1(14.9,15.2)$ & $92.0(88.2,95.9)$ \\
Q5 & $276 \pm 80.3$ & $61.8(61.3,62.3)$ & $1.63(1.61,1.65)$ & $15.2(15.1,15.3)$ & $96.1(92.3,99.9)$ \\
$P$-trend & - & $<0.01$ & 0.02 & $<0.01$ & $<0.01$ \\
Q5-Q1\% & - & 2.36 & 1.99 & 2.40 & 12.79
\end{tabular}

Vitamin E (mg/d)

Q1

$5.90 \pm 1.16$

$60.3(59.7,60.9)$

$1.58(1.56,1.61)$

$14.9(14.8,15.1)$

$60.7(60.2,61.2)$

$1.60(1.58,1.62)$

$61.3(60.8,61.8)$

$1.63(1.61,1.65)$

Q3

$10.7 \pm 0.64$

$61.2(60.7,61.8)$

$1.62(1.60,1.64)$

$61.9(61.2,62.5)$

$1.64(1.62,1.66)$

Q5

$18.3 \pm 3.39$

$P$-trend -

Q5-Q1\%

$<0.01$

2.60

$<0.01$

3.54

Total carotene $(\mu \mathrm{g} / \mathrm{d})$

Q1

$60.8(60.3,61.3) \quad 1.61(1.59,1.63)$

$60.9(60.4,61.4) \quad 1.61(1.59,1.63)$

$60.8(60.3,61.3) \quad 1.61(1.59,1.63)$

$61.6(61.1,62.1) \quad 1.63(1.61,1.65)$

$61.4(60.9,62.0)$

0.03

1.03

$1.62(1.60,1.64)$

0.11

0.96

$61.1(60.6,61.7)$

$1.62(1.60,1.64)$

$1.62(1.60,1.64)$

$1.60(1.58,1.62)$

$1.62(1.59,1.64)$

$15.1(14.9,15.2)$

$15.1(14.9,15.2)$

$15.0(14.9,15.2)$

$15.0(14.8,15.2)$

0.70

0.42

$14.9(14.7,15.0)$

$15.0(14.9,15.1)$

$15.0(14.9,15.2)$

$15.1(15.0,15.3)$

$15.1(14.9,15.2)$

0.01

1.44

$14.9(14.8,15.0)$

$15.0(14.9,15.1)$

$15.1(14.9,15.2)$

$15.0(14.9,15.2)$

$15.1(15.0,15.3)$

0.03

$-1.61$

$-0.02$

$1.60(1.58,1.63)$

$14.9(14.7,15.0)$

$15.0(14.9,15.2)$

$15.0(14.9,15.1)$

$15.1(15.0,15.3)$

$15.1(14.9,15.2)$

0.01

1.50

$15.1(14.9,15.3)$

$15.0(14.9,15.2)$

$15.0(14.8,15.1)$

$15.1(15.0,15.3)$

$14.9(14.8,15.1)$

0.23

$-1.30$

$-0.36$

0.14

0.91

$1.60(1.58,1.62)$

$14.9(14.8,15.0)$

$15.0(14.8,15.1)$
$89.2(84.8,93.6)$

$90.6(86.9,94.3)$

$91.9(88.1,95.8)$

$90.9(87.3,94.5)$

$91.6(87.1,96.2)$

0.54

2.77

$85.6(81.8,89.3)$

$91.2(87.7,94.8)$

$90.8(87.0,94.5)$

$94.8(91.1,98.4)$

$91.9(88.2,95.7)$

0.01

7.45

$88.1(84.6,91.7)$

$90.8(86.9,94.8)$

$91.8(88.3,95.3)$

$92.8(89.2,96.5)$

$90.7(86.9,94.4)$

0.24

2.85

$85.6(81.8,89.4)$ $91.4(87.8,94.9)$ $90.1(86.4,93.8)$ $95.3(91.6,98.9)$ $91.9(88.2,95.7)$ $<0.01$ 7.38

$92.1(88.1,96.2)$ $90.7(87.0,94.5)$ 89.7 (86.2,93.2) $90.8(87.2,94.3)$ $91.0(87.0,95.0)$ 0.78

$-1.24$

87.7 (84.0,91.4) $89.1(85.6,92.5)$ 
Table 2 (continued)

\begin{tabular}{llllll}
\hline & Intake $^{\mathrm{b}}$ & FFM $(\%)$ & FFM/BMI & FFMI $\left(\mathrm{kg} / \mathrm{m}^{\mathrm{b}}\right)$ & $\mathrm{LEP}^{\mathrm{c}}(\mathrm{w} / \mathrm{kg})$ \\
\hline Q3 & $146 \pm 25.2$ & $61.0(60.5,61.4)$ & $1.61(1.59,1.63)$ & $15.1(15.0,15.2)$ & $90.6(87.1,94.1)$ \\
Q4 & $234 \pm 36.4$ & $61.5(61.0,62.0)$ & $1.63(1.61,1.65)$ & $15.0(14.9,15.2)$ & $93.7(90.2,97.3)$ \\
Q5 & $499 \pm 230$ & $61.4(60.8,61.9)$ & $1.62(1.60,1.64)$ & $15.1(15.0,15.3)$ & $93.2(89.4,97.0)$ \\
$P$-trend & - & 0.03 & 0.22 & 0.03 & $<0.01$ \\
Q5-Q1\% & - & 1.09 & 0.87 & 1.50 & 6.30 \\
Lycopene $(\mu \mathrm{g} / \mathrm{d})$ & & & & \\
Q1 & $412 \pm 168$ & $61.0(60.4,61.5)$ & $1.61(1.59,1.63)$ & $15.0(14.8,15.1)$ & $87.2(83.7,90.7)$ \\
Q2 & $821 \pm 99.2$ & $61.3(60.8,61.8)$ & $1.63(1.61,1.65)$ & $15.0(14.8,15.1)$ & $91.5(87.4,95.5)$ \\
Q3 & $1161 \pm 100$ & $61.4(60.9,61.8)$ & $1.63(1.61,1.65)$ & $15.0(14.9,15.1)$ & $93.3(89.6,97.1)$ \\
Q4 & $1573 \pm 154$ & $61.2(60.7,61.6)$ & $1.62(1.60,1.63)$ & $15.1(14.9,15.2)$ & $89.8(86.2,93.4)$ \\
Q5 & $2771 \pm 1121$ & $60.6(60.1,61.2)$ & $1.59(1.57,1.61)$ & $15.1(15.0,15.3)$ & $92.5(88.5,96.5)$ \\
$P$-trend & - & 0.33 & 0.05 & 0.03 & 0.18 \\
Q5-Q1\% & - & -0.58 & -1.57 & 1.29 & 6.05 \\
Lutein +zeaxanthin $(\mu \mathrm{g} / \mathrm{d})$ & & & & \\
Q1 & $835 \pm 261$ & $60.5(60.0,61.1)$ & $1.59(1.57,1.61)$ & $15.0(14.8,15.1)$ & $88.4(84.6,92.2)$ \\
Q2 & $1462 \pm 153$ & $60.6(60.2,61.1)$ & $1.60(1.58,1.62)$ & $15.0(14.9,15.2)$ & $87.7(84.4,91.0)$ \\
Q3 & $1970 \pm 152$ & $61.1(60.6,61.6)$ & $1.62(1.60,1.64)$ & $15.0(14.9,15.2)$ & $90.3(86.8,93.8)$ \\
Q4 & $2602 \pm 216$ & $61.3(60.8,61.9)$ & $1.62(1.61,1.64)$ & $15.1(14.9,15.2)$ & $93.1(89.4,96.8)$ \\
Q5 & $4464 \pm 1744$ & $61.9(61.3,62.4)$ & $1.64(1.62,1.66)$ & $15.0(14.9,15.2)$ & $94.8(91.0,98.6)$ \\
$P$-trend & - & $<0.01$ & $<0.01$ & 0.37 & $<0.01$ \\
Q5-Q1\% & - & 2.27 & 3.15 & 0.52 & 7.23 \\
\hline
\end{tabular}

FFM fat-free mass, FFMI Fat Free Mass Index and LEP leg explosive power

${ }^{a}$ Values are adjusted means (least square means) \pm SE, $n=2570$. Means were adjusted for age, physical activity, smoking status, energy intake, protein intake and underreporting and Fat Free Mass Index was additionally adjusted for fat mass. Participant numbers by quintile were $\mathrm{Q} 1=514 ; \mathrm{Q} 2=514 ; \mathrm{Q} 3=514$; $\mathrm{Q} 4=514 ; \mathrm{Q} 5=514$

${ }^{\mathrm{b}}$ Intake values are unadjusted means $\pm \mathrm{SD}$

${ }^{c}$ Values are mean (least square means) $\pm \mathrm{SE}, n=1914$. Means were adjusted for age, physical activity, smoking status, energy intake, protein intake, underreporting, menopausal status, hormone replacement therapy and height. Participant numbers by quintile were Q1 $=383 ; \mathrm{Q} 2=383$; Q3 = 383; Q4=383; $\mathrm{Q} 5=382$

and strength range from $1 \%$, for skeletal muscle mass, and $3 \%$ for grip strength, for people over the age of 50 years [29]. Moreover, using standardised analyses to compare the different vitamins and protein, the associations were greatest for vitamin $\mathrm{C}$, despite mutual adjustment for all the nutrients investigated in our study, including protein intake. This research highlights the importance of dietary associations with muscle mass in individuals of all ages, supporting previous research that has shown that notable changes in skeletal muscle mass occur earlier in adult life (between 30 and 45 years of age) [30, 31].

The range of nutrients across quintiles of intake investigated in our study varied from 3.1 fold for vitamin E, and fourfold for vitamin C, to 4.6 fold for total carotene and to larger differences for retinol (10.4 fold). However, the associations with vitamin $\mathrm{E}$ intake were only found with FFM expressed either as a percentage or divided by BMI, and no associations were found with retinol.
Different foods contributed to intake of the nutrients investigated. Although vegetables were the most significant source, the specific vegetables contributing to these nutrients differed. The largest vegetable contributors to vitamin $C$ were peppers, Brussels sprouts and broccoli. For carotene the major vegetable sources were carrots and spinach whereas vitamin $E$ was supplied by avocado and mushrooms. Overall fruit was the greatest contributor to vitamin $\mathrm{C}$ intakes, and whole grain cereals were the greatest contributor to vitamin $\mathrm{E}$ intake. Our findings highlight the importance of eating a broad range of vegetables, fruits and whole grain cereal foods to achieve optimal intakes of vitamin $\mathrm{C}$, carotenes and vitamin $\mathrm{E}$. 
Table 3 Relative associations between indices of fat-free mass and leg explosive power calculated according to quantile of nutrient intake in 2570 females aged $18-79$ years, stratified by age ${ }^{a}$

\begin{tabular}{|c|c|c|c|c|c|c|}
\hline \multirow[b]{2}{*}{ Quintile of nutrient intake } & \multicolumn{2}{|l|}{ All $(n=2570)$} & \multicolumn{2}{|l|}{$<65$ years $(n=2346)$} & \multicolumn{2}{|l|}{$\geq 65$ years $(n=224)$} \\
\hline & $\beta(95 \% \mathrm{CI})$ & $P$-trend & $\beta(95 \% \mathrm{CI})$ & $P$-trend & $\beta(95 \% \mathrm{CI})$ & $P$-trend \\
\hline \multicolumn{7}{|l|}{ FFM $(\%)$} \\
\hline Vitamin C (mg/d) & $0.28(0.1,0.5)$ & $<0.01$ & $0.30(0.1,0.5)$ & $<0.01$ & $0.50(-0.5,1.5)$ & 0.32 \\
\hline Vitamin E (mg/d) & $0.41(0.2,0.6)$ & $<0.01$ & $0.41(0.2,0.7)$ & $<0.01$ & $0.31(-0.7,1.4)$ & 0.55 \\
\hline Total carotene $(\mu \mathrm{g} / \mathrm{d})$ & $0.14(0.0,0.3)$ & 0.12 & $0.13(-0.1,0.3)$ & 0.16 & $0.63(-0.2,1.5)$ & 0.14 \\
\hline Retinol ( $\mu \mathrm{g} / \mathrm{d})$ & $0.00(-0.2,0.2)$ & 0.99 & $-0.01(-0.2,0.2)$ & 0.92 & $0.32(-0.6,1.3)$ & 0.51 \\
\hline Protein $(\% \mathrm{E} / \mathrm{d})$ & $-0.32(-0.5,-0.2)$ & $<0.01$ & $-0.34(-0.5,-0.2)$ & $<0.01$ & $-0.50(-1.5,0.5)$ & 0.34 \\
\hline \multicolumn{7}{|l|}{$\mathrm{LEP}^{\mathrm{b}}(\mathrm{w} / \mathrm{kg})$} \\
\hline Vitamin C (mg/d) & $2.14(0.9,3.3)$ & $<0.01$ & $2.32(1.1,3.6)$ & $<0.01$ & $-1.06(-9.0,6.9)$ & 0.79 \\
\hline Vitamin E (mg/d) & $0.66(-1.0,2.3)$ & 0.43 & $0.60(-1.2,2.4)$ & 0.51 & $-0.76(-9.4,7.8)$ & 0.86 \\
\hline Total carotene $(\mu \mathrm{g} / \mathrm{d})$ & $1.35(0.1,2.6)$ & 0.03 & $1.67(0.4,2.9)$ & $<0.01$ & $-6.68(-15.0,1.6)$ & 0.11 \\
\hline Retinol ( $\mu \mathrm{g} / \mathrm{d})$ & $-0.23(-1.5,1.1)$ & 0.73 & $-0.39(-1.8,1.0)$ & 0.57 & $0.26(-8.8,9.4)$ & 0.95 \\
\hline Protein $(\% \mathrm{E} / \mathrm{d})$ & $-1.18(-2.3,0.0)$ & 0.04 & $-1.18(-2.4,0.0)$ & 0.05 & $-2.64(-8.6,3.3)$ & 0.38 \\
\hline \multicolumn{7}{|l|}{ FFMI $\left(\mathrm{kg} / \mathrm{m}^{2}\right)$} \\
\hline Vitamin C (mg/d) & $0.07(0.0,0.1)$ & $<0.01$ & $0.08(0.03,0.12)$ & $<0.01$ & $0.02(-0.3,0.3)$ & 0.91 \\
\hline Vitamin E (mg/d) & $0.00(-0.05,0.06)$ & 0.85 & $-0.01(-0.07,0.05)$ & 0.70 & $0.23(-0.1,0.6)$ & 0.17 \\
\hline Total carotene $(\mu \mathrm{g} / \mathrm{d})$ & $0.06(0.02,0.1)$ & $<0.01$ & $0.05(0.01,0.1)$ & 0.02 & $0.22(-0.03,0.46)$ & 0.09 \\
\hline Retinol ( $\mu \mathrm{g} / \mathrm{d})$ & $-0.03(-0.08,0.02)$ & 0.26 & $-0.04(-0.1,0.01)$ & 0.11 & $0.13(-0.16,0.43)$ & 0.38 \\
\hline Protein $(\% \mathrm{E} / \mathrm{d})$ & $0.03(-0.01,0.07)$ & 0.15 & $0.03(-0.01,0.1)$ & 0.14 & $0.05(-0.23,0.33)$ & 0.73 \\
\hline \multicolumn{7}{|l|}{ FFM/BMI } \\
\hline Vitamin C (mg/d) & $0.00(-0.0,0.01)$ & 0.08 & $0.01(-0.00,0.01)$ & 0.11 & $0.02(-0.01,0.05)$ & 0.26 \\
\hline Vitamin E (mg/d) & $0.01(0.0,0.02)$ & $<0.01$ & $0.02(0.01,0.03)$ & $<0.01$ & $-0.00(-0.04,0.04)$ & 0.96 \\
\hline Total carotene $(\mu \mathrm{g} / \mathrm{d})$ & $0.00(-0.0,0.0)$ & 0.49 & $0.00(-0.00,0.01)$ & 0.54 & $0.02(-0.01,0.05)$ & 0.24 \\
\hline Retinol $(\mu \mathrm{g} / \mathrm{d})$ & $0.00(-0.0,0.01)$ & 0.23 & $0.00(-0.00,0.01)$ & 0.24 & $0.01(-0.02,0.05)$ & 0.43 \\
\hline Protein $(\% \mathrm{E} / \mathrm{d})$ & $-0.02(-0.02,-0.01)$ & $<0.01$ & $-0.02(-0.02,-0.01)$ & $<0.01$ & $-0.02(-0.05,0.02)$ & 0.38 \\
\hline
\end{tabular}

FFM fat free mass and $L E P$ leg explosive power

${ }^{a}$ Values are adjusted beta coefficients $(95 \% \mathrm{CI})$ per quantile of intake, $n=2570$ (Quintiles for all ages and $<65$ years and tertiles for those $\geq 65$ year). Models were adjusted for age, physical activity, smoking status, energy intake and underreporting

${ }^{\mathrm{b}}$ Subset analysis $n=1914$ ( $<65$ years $n=1794 ; \geq 65$ years $n=120$ ). Means were adjusted for age, physical activity, smoking status, energy intake, underreporting, menopausal status, hormone replacement therapy and height. Dietary variables are expressed per quintile for all participants and participants $<65$ years and tertiles for participants $\geq 65$ years

\section{Comparison with Other Studies}

The positive associations we found between higher intakes of vitamin $\mathrm{C}$, carotenoids and vitamin $\mathrm{E}$ are, in the main, supported by the few previous human studies that investigated the relationships between intake or circulating concentrations of vitamin C, E or carotene and sarcopenic indices in cohorts of older people [11-14]. Dietary vitamin $\mathrm{C}$ was associated with measures of skeletal muscle function in the InCHIANTI Study, and in women only in the UK Hertfordshire Cohort Study (HCS) [11-14]. Circulating vitamin $\mathrm{C}$ and sarcopenic indices were only previously examined in elderly Japanese women where positive associations were found between measures of physical function but not FFM [13]. The only study investigating vitamin C intake with FFM found positive associations but only after 2.6 years of follow-up [11].

Circulating vitamin $\mathrm{E}$ was investigated in only three previous studies where plasma $\alpha$-tocopherol was positively associated with measures of grip and knee strength, performance or decline in physical function. However, two studies found no associations between intake of vitamin $\mathrm{E}$ and either grip strength or function [12, 14, 17, 32]. Our finding of a positive relationship with dietary vitamin $\mathrm{E}$ and certain indices of fat-free mass further supports the relevance of vitamin $\mathrm{E}$ to skeletal muscle health.

For carotenoids, two previous studies found associations with either circulating $\beta$ or total carotene and greater muscle strength or physical activity, with only one other study finding positive associations between higher intakes of carotene and strength or physical activity, in women [12, 14-19]. Our 
Fig. 2 The relative associations of vitamin $\mathrm{C}$, vitamin $\mathrm{E}$, retinol, carotene and protein with leg explosive power in 1914 females aged $18-79$ years, stratified by age ${ }^{1}$. Values represent the difference in standardised values of leg explosive power between participants in Q5 vs Q1 (T3-T1 for > 65 years sub-group) of intake with all nutrients included in the model. Values were also adjusted for age, physical activity, smoking status, energy intake, underreporting, height, menopausal status and use of hormone replacement therapy. $* P$-trend $<0.05$

Fig. 3 Foods that contributed to at least $10 \%$ of vitamin $\mathrm{C}$, vitamin $\mathrm{E}$, carotene and retinol intakes in 2570 females aged 18-79 years ${ }^{1}$. Values are the percentage contribution of individual foods to total nutrient intake. The main contributors to vegetable intakes were peppers, Brussels sprouts and broccoli for Vitamin C, avocado, mushrooms and spinach for Vitamin $\mathrm{E}$ and carrots and spinach for carotene. For Vita$\min \mathrm{C}$ the main contributors to fruit intakes were strawberries, oranges and grapefruit
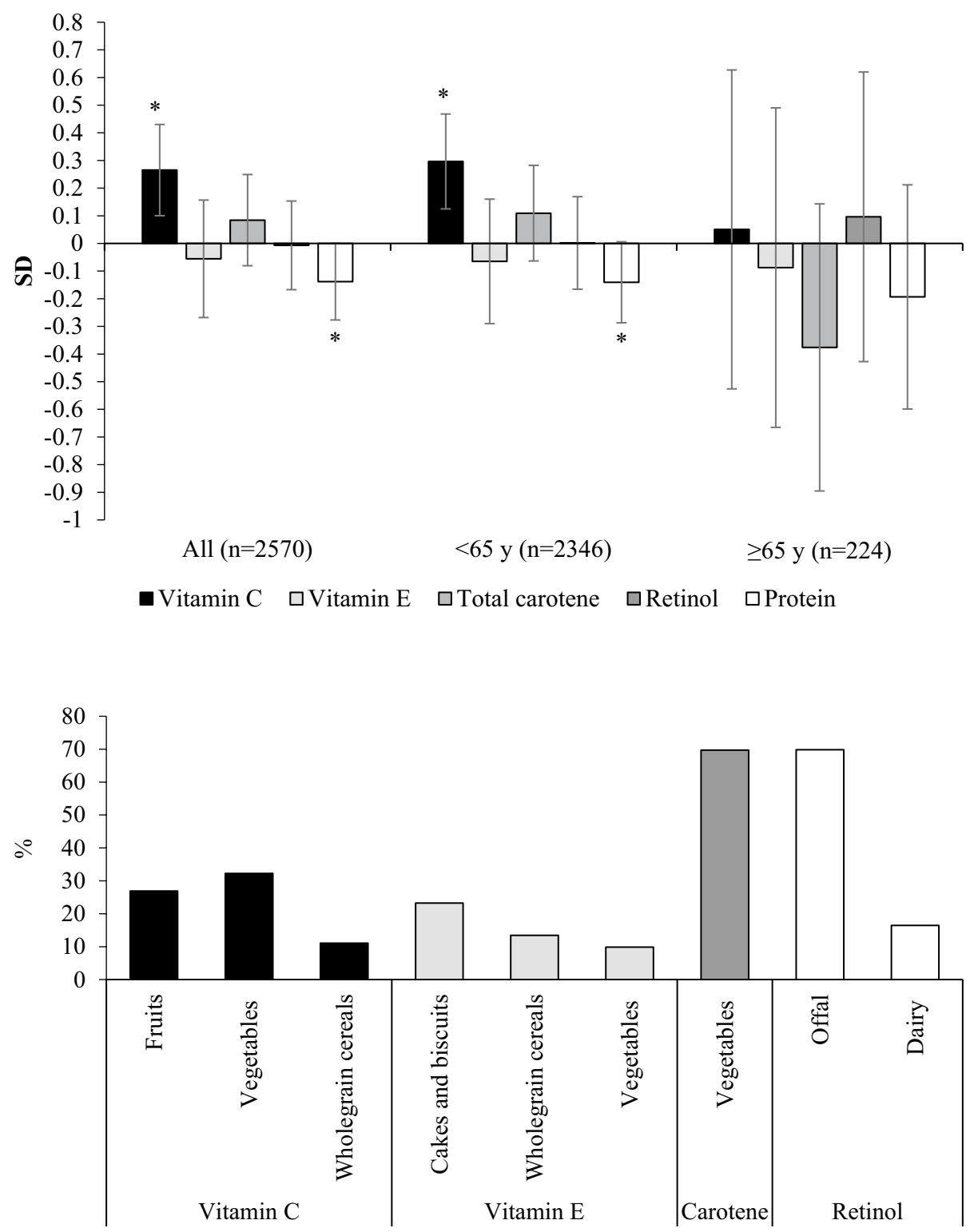

findings extend the previous research by identifying that the full range of carotenoids also have importance for skeletal muscle health.

The lack of association with retinol intake and sarcopenic indices found in our study contrasts with the only other human study that found greater intakes of retinol were significantly related to loss of appendicular lean mass [11].

In recent studies, relating intakes of either vitamin $\mathrm{C}, \mathrm{E}$, or circulating vitamin $\mathrm{E}$, to sarcopenia no associations were found [33-35] although greater prevalence of frailty was associated with either lower concentrations of carotenoids, retinol or $\alpha$-tocopherol, in a further three studies [36-39].

The reason for the lack of association between the vitamins in our study and grip strength, compared with the strong associations with LEP are not clear but may be due to LEP being a direct measure of lower limb strength and power which may be more sensitive to the effects of diet [29].

The lack of association between the vitamins and CRP in our study may be due to the relatively high intakes of vitamins, coupled with the relatively low blood concentrations of hsCRP in this population.

Although we also found smaller associations with the sarcopenic indices and protein intake than the vitamins in our standardised analyses, other studies have found protein is important for skeletal muscle. However, there has been variability in effectiveness of supplementation with protein in intervention studies, and protein intake in our study was higher, $1.3 \mathrm{~g}$ protein $/ \mathrm{kg} / \mathrm{d}$, than in other previous studies which may explain our findings [10, 40]. However, our findings relating to protein intake require further exploration. Nevertheless, our findings suggest that consuming 
sufficient antioxidant vitamins in addition to protein is important.

Despite the few previous studies, to our knowledge, our study is the first to investigate dietary intakes of vitamin $\mathrm{C}$, $\mathrm{E}, \mathrm{A}$ (retinol), individual carotenoids and protein, as well as circulating CRP with the full range of sarcopenic indices in both younger and older women.

\section{Physiological Mechanisms}

There is clear mechanistic relevance of the antioxidant vitamins on skeletal muscle health during aging which also supports our observational findings. Supplementation of lycopene, $\beta$-carotene or mixed antioxidant vitamins in animal experiments either had positive effects on muscle force or physical activity or attenuated oxidative stress or loss of skeletal muscle [41]. Vitamin E also had protective effects on exercise-induced oxidative damage in both young and older adults [7], and vitamin $\mathrm{C}$ had protective effects on oxidative biomarkers, inflammatory cytokines and CRP [42]. Beyond roles as an antioxidant and anti-inflammatory agent vitamin $\mathrm{C}$ is also integral to synthesis of collagen and of carnitine which is important for the metabolism of longchain fatty acids during physical activity [8].

\section{Deficiency of Vitamins and Supplementation}

Although the significant associations between intake of vitamins $\mathrm{C}, \mathrm{E}$ and carotenoids were found across the usual range of consumption, the women in the lowest quintile of vitamin $\mathrm{C}$ intake consumed less than the average requirement for vitamin $\mathrm{C}$ intake of $80 \mathrm{mg} / \mathrm{d}$ [43]. The prevalence of low intakes of vitamin $\mathrm{C}$, or circulating concentrations of vitamin $\mathrm{C}$ indicative of scurvy, is high in vulnerable older populations living in community and residential care $\sim 40 \%$ $[3,44]$. Moreover, consumption of 5 or more portions of fruits and vegetables a day is only $19 \%$ of those over the age of 75 years in the UK [45].

Whilst supraphysiological doses of vitamin $\mathrm{C}$ could be used to rectify low dietary intakes in older vulnerable groups these need to be used with caution due to the detrimental, prooxidant, effects of long-term high doses of vitamin $\mathrm{C}$ (>500 mg per day) compared the concentrations found naturally in foods [46]. There is also debate surrounding potential negative effects of supraphysiological doses of vitamin C on skeletal muscle function in athletes [47].

Our research has found that intake of antioxidant vitamins within the normal dietary range has important effects on sarcopenic indices, in the whole cohort and stratified analysis showed associations in younger women, provided by a different food groups. Given the shortfall in intakes of the antioxidant vitamins it is important to encourage greater intakes of the foods that supply them; namely vegetables, fruits and whole grain cereal foods, in addition protein for maintaining skeletal muscle health in populations of all ages. This is particularly important for vulnerable older people in the community and in residential care.

Strengths of this study include comprehensive measurements of diet in a well characterised large cohort which allowed us to examine for the first time associations between an extensive range of sarcopenic indices, including DXA-measured FFM, LEP and grip strength and a range of antioxidant vitamins, including all the carotenoids. We were also able to undertake a comparative analysis of the different nutrients allowing us to examine the independent associations with intake of each vitamin and protein. Limitations include the small number of women aged over 65 an imbalance between younger and older women in our cohort which future studies should address. In addition, this study was cross-sectional which limits inference for causation. We also did not account for the nutrients supplied by food supplements, however, our analyses indicate the importance of intake of vitamins supplied by diet alone. A further limitation is that we did not have directly measured physical activity, however, we used validated questionnaires, which although less precise than objective measures, do distinguish across the range of activity levels in individuals [28].

Although we were able to determine what dietary intakes are relevant for skeletal muscle health we lacked data on dietary biomarkers meaning we were unable to confirm our findings with blood or urinary levels.

\section{Conclusion}

For the first time in a free-living population, our research shows that higher dietary intake of the antioxidant vitamins, particularly vitamin $\mathrm{C}$, could be protective for both loss of skeletal muscle mass and power during aging, and have relevance for treatment and prevention of frailty and sarcopenia in women. It was notable that the observed associations were identified in women younger than 65 years. Our findings provide further encouragement for intervention trials as well as for following the healthy eating guidelines for protection of skeletal muscle mass and power in people of all ages.

Author Contributions Concept and design of study AAW, AJ, EK. Statistical analysis AJ. Drafting of manuscript AAW, AJ. All authors commented on the manuscript and contributed to the study.

Funding This study was funded by $\mathrm{PhD}$ funding from the University of East Anglia. TwinsUK is funded by the Wellcome Trust (Grant WT081878MA). Medical Research Council, European Union, the National Institute for Health Research (NIHR)-funded BioResource, 
Clinical Research Facility, and Biomedical Research Centre based at Guy's and St Thomas' NHS Foundation Trust in partnership with King's College London.

\section{Compliance with Ethical Standards}

Conflict of interest Ailsa Welch, Amy Jennings, Eirini Kelaiditi, Jane Skinner and Claire Steves declare no conflicts of interest.

Human and Animal Rights and Informed Consent This study was approved by the St Thomas's Hospital Research Ethics Committee and all participants provided written informed consent.

Open Access This article is licensed under a Creative Commons Attribution 4.0 International License, which permits use, sharing, adaptation, distribution and reproduction in any medium or format, as long as you give appropriate credit to the original author(s) and the source, provide a link to the Creative Commons licence, and indicate if changes were made. The images or other third party material in this article are included in the article's Creative Commons licence, unless indicated otherwise in a credit line to the material. If material is not included in the article's Creative Commons licence and your intended use is not permitted by statutory regulation or exceeds the permitted use, you will need to obtain permission directly from the copyright holder.To view a copy of this licence, visit https://creativecommons.org/licenses/by/4.0/.

\section{References}

1. Cruz-Jentoft AJ, Bahat G, Bauer J, Boirie Y, Bruyere O, Cederholm T, Cooper C, Landi F, Rolland Y, Sayer AA, Schneider SM, Sieber CC, Topinkova E, Vandewoude M, Visser M, Zamboni M, Writing Group for the European Working Group on Sarcopenia in Older P, the Extended Group for E (2019) Sarcopenia: revised European consensus on definition and diagnosis. Age Ageing 48(1):16-31. https://doi.org/10.1093/ageing/afy 169

2. Landi F, Camprubi-Robles M, Bear DE, Cederholm T, Malafarina V, Welch AA, Cruz-Jentoft AJ (2018) Muscle loss: the new malnutrition challenge in clinical practice. Clin Nutr. https://doi. org/10.1016/j.clnu.2018.11.021

3. Bunn D, Hooper L, Welch A (2018) Dehydration and malnutrition in residential care: recommendations for strategies for improving practice derived from a scoping review of existing policies and guidelines. Geriatrics 3(4):77

4. Cesari M, Araujo de Carvalho I, Amuthavalli Thiyagarajan J, Cooper C, Martin FC, Reginster JY, Vellas B, Beard JR (2018) Evidence for the domains supporting the construct of intrinsic capacity. J Gerontol A Biol Sci Med Sci 73(12):1653-1660. https ://doi.org/10.1093/gerona/gly011

5. Dalle S, Rossmeislova L, Koppo K (2017) The role of inflammation in age-related sarcopenia. Front Physiol 8:1045. https://doi. org/10.3389/fphys.2017.01045

6. Chapman MA, Meza R, Lieber RL (2016) Skeletal muscle fibroblasts in health and disease. Differentiation 92(3):108-115. https ://doi.org/10.1016/j.diff.2016.05.007

7. Chung E, Mo H, Wang S, Zu Y, Elfakhani M, Rios SR, Chyu MC, Yang RS, Shen CL (2018) Potential roles of vitamin E in age-related changes in skeletal muscle health. Nutr Res 49:23-36. https://doi.org/10.1016/j.nutres.2017.09.005

8. Rebouche CJ (1152S) Ascorbic acid and carnitine biosynthesis. Am J Clin Nutr 54(6 Suppl):1147S-1152S. https://doi. org/10.1093/ajcn/54.6.1147s
9. Cruz-Jentoft AJ, Woo J (2019) Nutritional interventions to prevent and treat frailty. Curr Opin Clin Nutr Metab Care. https://doi. org/10.1097/MCO.0000000000000556

10. Thomas DK, Quinn MA, Saunders DH, Greig CA (2016) Protein supplementation does not significantly augment the effects of resistance exercise training in older adults: a systematic review. J Am Med Dir Assoc 17(10):959e951-959. https://doi. org/10.1016/j.jamda.2016.07.002

11. Scott D, Blizzard L, Fell J, Giles G, Jones G (2010) Associations between dietary nutrient intake and muscle mass and strength in community-dwelling older adults: the Tasmanian Older Adult Cohort Study. J Am Geriatr Soc 58(11):2129-2134. https://doi. org/10.1111/j.1532-5415.2010.03147.x

12. Martin H, Aihie Sayer A, Jameson K, Syddall H, Dennison EM, Cooper C, Robinson S (2011) Does diet influence physical performance in community-dwelling older people? Findings from the Hertfordshire Cohort Study. Age Ageing 40(2):181-186. https:// doi.org/10.1093/ageing/afq175

13. Saito K, Yokoyama T, Yoshida H, Kim H, Shimada H, Yoshida Y, Iwasa H, Shimizu Y, Kondo Y, Handa S, Maruyama N, Ishigami A, Suzuki T (2012) A significant relationship between plasma vitamin $\mathrm{C}$ concentration and physical performance among Japanese elderly women. J Gerontol A Biol Sci Med Sci 67(3):295-301. https://doi.org/10.1093/gerona/glr174

14. Robinson SM, Jameson KA, Batelaan SF, Martin HJ, Syddall HE, Dennison EM, Cooper C, Sayer AA (2008) Diet and its relationship with grip strength in community-dwelling older men and women: the Hertfordshire cohort study. J Am Geriatr Soc 56(1):84-90. https://doi.org/10.1111/j.1532-5415.2007.01478.x

15. Cesari M, Pahor M, Bartali B, Cherubini A, Penninx BW, Williams GR, Atkinson H, Martin A, Guralnik JM, Ferrucci L (2004) Antioxidants and physical performance in elderly persons: the Invecchiare in Chianti (InCHIANTI) study. Am J Clin Nutr 79(2):289-294

16. Lauretani F, Semba RD, Bandinelli S, Dayhoff-Brannigan M, Giacomini V, Corsi AM, Guralnik JM, Ferrucci L (2008) Low plasma carotenoids and skeletal muscle strength decline over 6 years. J Gerontol A Biol Sci Med Sci 63(4):376-383

17. Semba RD, Blaum C, Guralnik JM, Moncrief DT, Ricks MO, Fried LP (2003) Carotenoid and vitamin E status are associated with indicators of sarcopenia among older women living in the community. Aging Clin Exp Res 15(6):482-487

18. Semba RD, Varadhan R, Bartali B, Ferrucci L, Ricks MO, Blaum C, Fried LP (2007) Low serum carotenoids and development of severe walking disability among older women living in the community: the women's health and aging study I. Age Ageing 36(1):62-67. https://doi.org/10.1093/ageing/afl122

19. Alipanah N, Varadhan R, Sun K, Ferrucci L, Fried LP, Semba RD (2009) Low serum carotenoids are associated with a decline in walking speed in older women. J Nutr Health Aging 13(3):170-175

20. Moayyeri A, Hammond CJ, Valdes AM, Spector TD (2013) Cohort profile: Twins UK and healthy ageing twin study. Int $\mathrm{J}$ Epidemiol 42(1):76-85. https://doi.org/10.1093/ije/dyr207

21. McCance RA, Widdowson EM, Holland B, Welch AA, Buss DH, Great Britain Ministry of Agriculture F, Food (1991) McCance and Widdowson's the composition of foods, 5th rev \& extended. Royal Society of Chemistry, London

22. Hayhoe RPG, Lentjes MAH, Mulligan AA, Luben RN, Khaw KT, Welch AA (2017) Carotenoid dietary intakes and plasma concentrations are associated with heel bone ultrasound attenuation and osteoporotic fracture risk in the European Prospective Investigation into Cancer and Nutrition (EPIC)-Norfolk cohort. Br J Nutr 117(10):1439-1453. https://doi.org/10.1017/S0007 114517001180 
23. Otten JJ, Hellwig JP, Meyers LD (2006) DRI, dietary reference intakes: the essential guide to nutrient requirements. National Academies Press, Washington, D.C.

24. Arden NK, Spector TD (1997) Genetic influences on muscle strength, lean body mass, and bone mineral density: a twin study. J Bone Miner Res 12(12):2076-2081. https://doi. org/10.1359/jbmr.1997.12.12.2076

25. Bassey EJ, Short AH (1990) A new method for measuring power output in a single leg extension: feasibility, reliability and validity. Eur J Appl Physiol Occupational Physiol 60(5):385-390

26. MacGregor AJ, Gallimore JR, Spector TD, Pepys MB (2004) Genetic effects on baseline values of $\mathrm{C}$-reactive protein and serum amyloid a protein: a comparison of monozygotic and dizygotic twins. Clin Chem 50(1):130-134. https://doi. org/10.1373/clinchem.2003.028258

27. Cherkas LF, Hunkin JL, Kato BS, Richards JB, Gardner JP, Surdulescu GL, Kimura M, Lu X, Spector TD, Aviv A (2008) The association between physical activity in leisure time and leukocyte telomere length. Arch Intern Med 168(2):154-158. https://doi.org/10.1001/archinternmed.2007.39

28. Wareham NJ, Jakes RW, Rennie KL, Schuit J, Mitchell J, Hennings S, Day NE (2003) Validity and repeatability of a simple index derived from the short physical activity questionnaire used in the European Prospective Investigation into Cancer and Nutrition (EPIC) study. Public Health Nutr 6(04):407-413. https://doi. org/10.1079/PHN2002439

29. Mitchell WK, Williams J, Atherton P, Larvin M, Lund J, Narici M (2012) Sarcopenia, dynapenia, and the impact of advancing age on human skeletal muscle size and strength; a quantitative review. Front Physiol 3:260. https://doi.org/10.3389/fphys.2012.00260

30. Cesari M, Pahor M (2008) Target population for clinical trials on sarcopenia. J Nutr Health Aging 12(7):470-478. https://doi. org $/ 10.1007 / \mathrm{bf} 02982708$

31. Janssen I, Heymsfield SB, Wang ZM, Ross R (2000) Skeletal muscle mass and distribution in 468 men and women aged 18-88 year. J Appl Physiol (1985) 89(1):81-88. https://doi.org/10.1152/ jappl.2000.89.1.81

32. Bartali B, Frongillo EA, Guralnik JM, Stipanuk MH, Allore HG, Cherubini A, Bandinelli S, Ferrucci L, Gill TM (2008) Serum micronutrient concentrations and decline in physical function among older persons. JAMA 299(3):308-315. https://doi. org/10.1001/jama.299.3.308

33. Chaput JP, Lord C, Cloutier M, Aubertin Leheudre M, Goulet ED, Rousseau S, Khalil A, Dionne IJ (2007) Relationship between antioxidant intakes and class I sarcopenia in elderly men and women. J Nutr Health Aging 11(4):363-369

34. Verlaan S, Aspray TJ, Bauer JM, Cederholm T, Hemsworth J, Hill TR, McPhee JS, Piasecki M, Seal C, Sieber CC, Ter Borg S, Wijers SL, Brandt K (2017) Nutritional status, body composition, and quality of life in community-dwelling sarcopenic and non-sarcopenic older adults: a case-control study. Clin Nutr 36(1):267-274. https://doi.org/10.1016/j.clnu.2015.11.013

35. Ter Borg S, de Groot LC, Mijnarends DM, de Vries JH, Verlaan S, Meijboom S, Luiking YC, Schols JM (2016) Differences in nutrient intake and biochemical nutrient status between sarcopenic and nonsarcopenic older adults-results from the maastricht sarcopenia study. J Am Med Dir Assoc. https://doi.org/10.1016/j. jamda.2015.12.015

36. Semba RD, Bartali B, Zhou J, Blaum C, Ko CW, Fried LP (2006) Low serum micronutrient concentrations predict frailty among older women living in the community. J Gerontol Ser A Biol Sci Med Sci 61(6):594-599

37. Michelon E, Blaum C, Semba RD, Xue QL, Ricks MO, Fried LP (2006) Vitamin and carotenoid status in older women: associations with the frailty syndrome. J Gerontol A Biol Sci Med Sci 61(6):600-607

38. Ble A, Cherubini A, Volpato S, Bartali B, Walston JD, Windham BG, Bandinelli S, Lauretani F, Guralnik JM, Ferrucci L (2006) Lower plasma vitamin $\mathrm{E}$ levels are associated with the frailty syndrome: the InCHIANTI study. J Gerontol A Biol Sci Med Sci 61(3):278-283

39. Pilleron S, Weber D, Peres K, Colpo M, Gomez-Cabrero D, Stuetz W, Dartigues JF, Ferrucci L, Bandinelli S, Garcia-Garcia FJ, Grune T, Feart C, Initiative F (2018) Patterns of circulating fatsoluble vitamins and carotenoids and risk of frailty in four European cohorts of older adults. Eur J Nutr. https://doi.org/10.1007/ s00394-017-1602-0

40. Houston DK, Nicklas BJ, Ding J, Harris TB, Tylavsky FA, Newman AB, Lee JS, Sahyoun NR, Visser M, Kritchevsky SB (2008) Dietary protein intake is associated with lean mass change in older, community-dwelling adults: the Health, Aging, and Body Composition (Health ABC) Study. Am J Clin Nutr 87(1):150-155

41. van Dijk M, Dijk FJ, Hartog A, van Norren K, Verlaan S, van Helvoort A, Jaspers RT, Luiking Y (2018) Reduced dietary intake of micronutrients with antioxidant properties negatively impacts muscle health in aged mice. J Cachexia Sarcopenia Muscle 9(1):146-159. https://doi.org/10.1002/jcsm.12237

42. Block G, Jensen CD, Dalvi TB, Norkus EP, Hudes M, Crawford PB, Holland N, Fung EB, Schumacher L, Harmatz P (2009) Vitamin $C$ treatment reduces elevated C-reactive protein. Free Radic Biol Med 46(1):70-77. https://doi.org/10.1016/j.freeradbio med.2008.09.030

43. EFSA (2013) Scientific opinion on dietary reference values for vitamin C. EFSA J 11(11):3418

44. Schleicher RL, Carroll MD, Ford ES, Lacher DA (2009) Serum vitamin $\mathrm{C}$ and the prevalence of vitamin $\mathrm{C}$ deficiency in the United States: 2003-2004 National Health and Nutrition Examination Survey (NHANES). Am J Clin Nutr 90(5):1252-1263. https://doi.org/10.3945/ajcn.2008.27016

45. England PH (2019) National diet and nutrition survey. https:// www.gov.uk/government/statistics/national-diet-and-nutritionsurvey-results-from-years-1-to-4-combined-of-the-rolling-progr amme-for-2008-and-2009-to-2011-and-2012. Accessed 24 April 2019

46. Osiecki M, Ghanavi P, Atkinson K, Nielsen LK, Doran MR (2010) The ascorbic acid paradox. Biochem Biophys Res Commun 400(4):466-470. https://doi.org/10.1016/j.bbrc.2010.08.052

47. Mason SA, Morrison D, McConell GK, Wadley GD (2016) Muscle redox signalling pathways in exercise. Role of antioxidants. Free Radic Biol Med 98:29-45. https://doi.org/10.1016/j.freer adbiomed.2016.02.022

Publisher's Note Springer Nature remains neutral with regard to jurisdictional claims in published maps and institutional affiliations. 